\title{
The Significance of Seismic Wavespeed Minima and Thermal Maxima in the
} Mantle and the Role of Dynamic Melting

Don L. Anderson ${ }^{a}$ and Charles G. Sammis ${ }^{b}$

${ }^{a}$ Seismological Laboratory, California Institute of Technology, Pasadena, CA 891125 , USA

9 'Department of Earth Sciences, University of Southern California, Los Angeles, 10 CA 90089-0740, USA 


\section{Abstract}

18 It is widely assumed that the boundary layer above the core is the source of intraplate volcanoes 19 such as Hawaii, Samoa and Yellowstone and that the sub-plate boundary layer at the top of the 20 mantle is thin and entirely subsolidus. In fact, this layer is thicker and has higher expansivity, 21 buoyancy and insulating power than the lower one, and may have higher potential temperatures. The 22 observed seismic structure of the low-velocity zone (LVZ) including attenuation, anisotropy, sharp 23 boundaries and a reduction of both compressional and shear moduli can be taken as strong evidence 24 for the ubiquitous presence of melt in the upper mantle. If the LVZ contains as little as $1-2 \%$ melt 25 then it is the most plausible and accessible source for mid-plate magmas; deeply rooted active 26 upwellings are unnecessary. The upper boundary layer is also the most plausible source of ancient 27 isotopic signatures of these magmas and their inclusions. 


\section{Introduction}

30 Seismological arguments for a melt component in the upper mantle extend back nearly 50 years (1-

31 3). It was realized that, while normal P-T gradients in the mantle cause a minimum_of seismic 32 wavespeeds at depths between about 100 and $200 \mathrm{~km}$, the actual properties of this region require 33 something more. By 1970 geophysicists had shown that the missing ingredient is probably athermal, 34 such as stress- and volatile-enhanced melting (1-6). Low velocity zones in the mantle are now routinely 35 attributed to dehydration melting although $\mathrm{CO}_{2}$ and dynamic melting may play important roles. The 36 theory for the interaction of elastic waves with partially molten rock was well developed prior to 1970

37 (1, 5, 7), and provides a self-consistent explanation of reduced seismic velocities, increased anisotropy, 38 and high attenuation of seismic waves in the low velocity zone. An elastic wave can be viewed as a time 39 dependent stress and temperature perturbation to the thermodynamic state of the medium $(1,7,8)$. In

40 regions near the melting point it can promote a small amount of crystallization or melting. The 41 associated volume change introduces a strain in the medium, which lowers the ratio of stress to strain 42 resulting in a reduced seismic velocity. This magnifies the effect of a small amount of melt on 43 wavespeeds beyond that given by simple static volume averaging $(1,5,9)$.

44 The precipitous change in elastic velocities at the onset of partial melting explains the sharp 45 vatiable-depth boundaries of the $\mathrm{LVZ}_{2}$ the $\mathrm{G}$ and the $\mathrm{L}$ discontinuities. The global $\mathrm{G}$ discontinuity at the 46 top of the LVZ is an abrupt 7-8\% reduction in short-period shear-wave speeds, which has been attributed 47 to sub-horizontal melt-rich lamellae (10). Comparable drops are inferred for compressional waves. The 48 existence of converted phases from the lid-LVZ interface provides evidence that the interface is sharp, 49 not diffuse as is expected at the lithosphere-asthenosphere boundary, which represents the transition 50 from long-term strength to weakness on geological time scales. Waveform modeling indicates seismic 51 velocity drops of up to $10-20 \%$ (11). Beneath the central Pacific, shear wave reverberations imply 52 abrupt 5-14\% velocity drops at depths that vary from 66 to $80 \mathrm{~km} \mathrm{(12),} \mathrm{and} \mathrm{a} \mathrm{further} 8-9 \%$ gradual 53 decrease from the top of the LVZ to about $160 \mathrm{~km}(13,14)$. Below continental shields, the upper 54 boundary of the LVZ is depressed to $150 \mathrm{~km}$.

55 If $\mathrm{G}$ and $\mathrm{L}$ represent boundaries of the partial melt zone $(9,12-14)$, the implication is that volatiles 56 have drained upwards and the melt content decreases with depth below the axis of the LVZ (Fig. 1). 57 Melts can be shear-driven and compaction-driven as well as buoyancy-driven. In other words, volcanoes 58 can be, and probably are, the result of stresses and fractures associated with plate tectonics rather than 59 localized 'hotspots'. This tectonic paradigm has been challenged recently by arguments that melts do not 
60 occur in the LVZ, that they drain out quickly, or that the effect is too small to explain the seismic 61 observations (15-17). These arguments ignore the importance of interactions of stress waves with small 62 melt fractions $(5,18)$ in the transmitting media, interactions of migrating melts with the matrix and the 63 role of impermeable interfaces.

64 The competing paradigm is that only mantle plumes are hot enough to produce melt and to have 65 sufficiently deep roots to supply magmas with ancient-enriched and "undegassed" mantle isotope 66 signatures. These geochemical inferences are based on implausible assumptions about ambient mantle,

67 the geotherm, the mode of mantle convection, and the nature and physical state of the surface boundary 68 layer (19), which is usually ignored.

\section{Analog experiments}

The response of a partially molten solid to the transmission of elastic waves is different from that of 72 a fluid-saturated but unreactive porous solid $(1,8)$. Several studies have determined the variation of 73 elaptic wave velocities across the melting point (1, 17, 18-23) (Fig. 2). Note the abrupt drops in 74 wavespeeds at the eutectic temperature. Similar effects may explain the G - or Gutenberg discontinuity, 75 and other LVZs associated with phase changes in the deeper mantle, but a solid-melt interface is not 76 required ) $(7,8)$. Additional details on relevant analog experiments and a discussion of deep LVZs are in 77 the Appendix.

\section{Geochemistry}

80 The upper boundary layer of the mantle is composed primarily (>97\%) of refractory high-melting 81 lithologies, e.g. dunite or harzburgite, that collect at the top of the mantle because they are buoyant and 82 which may trap fragments of ancient mantle, including high ${ }^{3} \mathrm{He} /{ }^{4} \mathrm{He}$ gases or low-U,Th inclusions $(9$, $8324,25)$. The interleaved low rigidity layers probably account for $1-2 \%$ of the volume, and may be 84 pyroxenite, magma-mush lenses, sills, metasomatic lamellae or fine-grained shear zones, which are 85 large-scale versions of the veins in metasomatized 'lithosphere'. Trace "exotic" components, such as 86 sulfides, oxides, carbonatites and fluid inclusions collect in the surface layers because of their solubility, 87 density, mobility and volatility and appear to resolve the various U-Pb-He-heatflow, ocean island basalt 88 and delayed core-formation paradoxes $(19,24,26-28)$. Although the highest potential temperatures in 89 the mantle are likely to coincide with the $\operatorname{LVZ}(24,29)$, low-melting fertile lithologies such as dense 90 eclogites and pyroxenites collect at the base of the transition zone. The potential temperature of any 
91 volume in the mantle is the temperature that that volume would have if it were compressed or expanded

92 to some reference pressure. It is often erroneously assumed in the petrological literature that this is the 93 extension of an actual sub-plate adiabatic geotherm.

94 The canonical models of mantle geochemistry and petrology assume that, except under ridges 95 (melting due to decompression melting), trenches (melting due to water induced melting) and hotspots 96 (melting due to anomalous temperature), the upper mantle is entirely subsolidus $(5,30,31)$ and that the 97 boundary layer above the core is the most plausible source of intraplate volcanoes such as Hawaii, 98 Samoa and Yellowstone (30, 32-34). The so-called basal mélange is assumed to be the largest, hottest, 99 most accessible, least degassed and most "primordial" (defined as having ${ }^{3} \mathrm{He} /{ }^{4} \mathrm{He}$ ratios higher than an 100 average mid-ocean-range basalt MORB) part of the mantle. From classical physics and logical points of 101 view (19) these assumptions are based on a number of questionable premises: 1) upper mantle geotherms 102 cannot cross the solidi of mantle minerals, and cannot exceed $\sim 1400{ }^{\circ} \mathrm{C}$ or temperatures assigned to sub103 ridge mantle $(31,35-38), 2)$ high ${ }^{3} \mathrm{He} /{ }^{4} \mathrm{He}$ ratios in mid-plate magmas relative to those in average MORB 104 are due to excess ${ }^{3} \mathrm{He}$ (not low ${ }^{4} \mathrm{He}$ ), and 3) most of the mantle supports an adiabatic gradient and is not 105 cooling with time. However, geotherms depend on thermal history and on the distribution of radioactive 106 elements. Internal heating, and by inference, secular cooling modulated by internal heating, lead to a 107 temperature maximum in the shallow mantle, and a subadiabatic gradient throughout most of the mantle 108 (29,39-41)._This thermal max results in an inverted geotherm, or overshoot, which probably coincides 109 with the LVZ (Fig. 1). The base of the surface boundary layer and the base of the mantle cannot be 110 assumed to be non-cooling isotherms $(31,41)$.

111 High ${ }^{3} \mathrm{He} /{ }^{4} \mathrm{He}$ ratios in mid-plate magmas relative to those in average MORB cannot be taken as 112 evidence that they have a deep origin $(9,24,26)$. Basalt isotope chemistry is controlled by mixing of 113 components (26), but both mixing relations and isotope evolution trajectories are indifferent as to the 114 location, depth, size and absolute compositions of the components. This means that the mixture of a high $115{ }^{3} \mathrm{He} /{ }^{4} \mathrm{He}-\mathrm{low}{ }^{3} \mathrm{He}$ component, long resident in the shallow mantle, and a high ${ }^{3} \mathrm{He}-\mathrm{low}{ }^{3} \mathrm{He} /{ }^{4} \mathrm{He}$ 116 component such as MORB is indistinguishable from the signatures attributed to deep undegassed or 117 primordial mantle sources.

118

\section{The Geotherm}

I20 Curve fitting assumptions, adjustments of the data, anelastic corrections, experimental errors and 121 theoretical oversights have led to the view that ambient midplate upper mantle is colder and less variable 
122 than a straightforward analysis of bathymetric and seismic data would indicate (18-21). Cambridge

123 geotherms, for example, are required to converge at depth, and to be asymptotic to the MORB adiabat

$124(31,35)$. In other words, temperatures are forced to bend as they approach $1400^{\circ} \mathrm{C}$ or an a priori adiabat.

125 Such constrained temperatures are more than $300{ }^{\circ} \mathrm{C}$ lower than would be inferred from the same data

126 without this enforced bend $(36,37)$. This has led to the view that temperatures that are higher than the

127 constrained adiabats are anomalous and require deep mantle sources.

128 Both vertical and lateral temperature gradients are high in conduction boundary layers. Basalts

129 derived from $150 \mathrm{~km}$ depth in a mature boundary layer will, in general, be hotter than those derived from

$13060 \mathrm{~km}$ depth but may involve lower extents of melting (42). A given isotherm deepens with time. There

131 are several lines of evidence that sub-boundary layer temperatures, however, increase away from ridges

132 toward plate interiors. The central Pacific has much lower upper mantle wavespeeds and higher inferred

133 temperatures than other oceans and than global reference models (43). Near-ridge mantle below $200 \mathrm{~km}$

134 depth has higher shear velocities, on average, than midplate upper mantle $(24,43,44)$. Bathymetry data

135 yields mantle temperatures for 'normal' regions of the north Pacific that are $\sim 200^{\circ} \mathrm{C}$ higher than the

136 constrained temperatures $(16,31,38,45)$. Subsidence rates and residual bathymetry of the younger

137 portions of plates imply that sub-ridge mantle is denser, on average, and in the southern oceans, than

138 mantle under older plates. Geophysical data are consistent with petrological inferences that near-ridge

139 mantle and midplate mantle temperatures differ, on average, by $>100^{\circ} \mathrm{C}$ but also show that the higher

140 temperatures are widespread and reflect ambient mantle under plates while lower temperatures appear to

141 preferentially occur under young oceanic plates or to be sampled by midplate volcanoes that extract

142 magma from the upper parts of the boundary layer. Hawaii, therefore, is not a localized thermal anomaly

143 associated with a plume; it is a small-scale sample of a deep portion of ambient midplate boundary layer

144 mantle $(24,46,47)$. Its location and magma output are controlled by a step in the thickness of the plate at

145 the wide Molokai fracture zone (48), and by stresses in the plate, not by conditions at the core-mantle 146 boundary.

147 The maximum depth of melting, and inferred source temperature, of oceanic magmas increases, and 148 the fraction of melt decreases, with plate age $(42,46)$. The P-T-depth-age trajectories calculated for 149 midplate magmas track the $1500-1600^{\circ} \mathrm{C}$ cooling half-space isotherms, rather than the predicted $1300^{\circ} \mathrm{C}$

150 horizontal isotherm $(24,45)$. Petrological and seismic data are consistent with midplate magmas being

151 extracted from within and near the base of the boundary layer, which has maximum temperatures some

$152 \sim 200^{\circ} \mathrm{C}$ higher than generally assumed for ambient mantle. On the other hand the low temperatures, low 
153 diffusivity, and high strength and buoyancy of the outer part of the shell mean the upper boundary layer

154 is also the most plausible place to preserve ancient enriched, isotopic signatures. These considerations 155 turn canonical geochemical models on their heads $(30,32-34,49)$ and remove what have been 156 considered as geochemical paradoxes and inconsistencies between geochemical and geophysical models.

\section{Discussion}

159 It is significant that the magnitude of the anisotropy in the LVZ is about the same as the drop in 160 wavespeed at the lid-LVZ boundary (the G-discontinuity). This supports the sheared multiphase 161 aggregate model with low-rigidity oriented lamellae $(10,24,50)$. In such a model, melt segregates into 162 sub-horizontal layers that lubricate plate motion. This interpretation is further supported by observations 163 of strong heterogeneity above $200 \mathrm{~km}$ depth and the numerous reflections, both S- wave and P-wave 164 between 100 and $200 \mathrm{~km}$ depth. The number of reflections in this depth range exceeds the number 165 observed near $400 \mathrm{~km}$ depth (51). Variations in $\mathrm{V}_{\underline{\underline{p}}}$ of $7.8 \%$, in $\mathrm{Vs}_{\mathrm{s}}$ of $14.5 \%$ and in $\mathrm{Vp} / \mathrm{Vs}$ of $7.2 \%$ 166 correspond to very high temperature variations, 850 to $960 \mathrm{~K}$, or small amounts of melt.

Anisotropy and strong reflections at the boundaries of the LVZ are best explained by large lenses of aligned/segregated melt accumulations [LLAMA] $(9,10,24,50)$. The interface (the G-discontinuity) and the L-discontinuity correspond to solidi, solidification or zone-refined fronts or volatile-no-volatile boundaries. Others have equated the much thinner mechanical boundary layer and the lithosphere to the lid (16) and sought to explain rheological transitions in terms of water content, grain size or

172 thermal/compositional effects $(36,52,53)$. The sharp boundaries, anisotropy and bulk modulus of the

173 LVZ cannot be explained with these effects or with simple static volume averaging schemes.

Melt-rich layers in a sheared mélange are tilted relative to the shear plane (54) This explains shearwave splitting and the apparent tilts of low wavespeed features in the mantle. It has been argued that that

176 gravity will effectively drain out all the melt along these tilted interfaces and that gravity-driven fluid 177 dynamic instabilities will destroy any such layers that survive (15). However, the melt channels are 178 probably not continuous, they react with the matrix and they are constantly reforming in the shear field.

Volume changing solid-solid and liquid-solid phase transformations can be effective in lowering 181 can be large. The main question is, can a high frequency seismic wave change the thermodynamic state 182 fast enough so that volume changes occur in the medium? Since the effect is measured at laboratory 
183 frequencies $(1,21)$, the answer is probably yes. The fact that the absorption band overlaps the seismic 184 band (9) supports this conclusion.

185 If melt is concentrated in thin lamellae, only about $1-2$ vol. \% is required to account for the 186 amplitudes of the observed reflections and anisotropy $(9,10,24)$. This is greater than the static 187 equilibrium melt fraction at the mantle temperatures and compositions that are assumed in petrological 188 models (16). However, the BL may be hotter or of different composition than in the experiments $(6,19$, 189 46). The melt fraction in LLAMA may also be enhanced by accumulation of melts that have migrated or 190 been sheared in from greater depths or zone-refined in from above.

191 High-resolution seismic imaging (10,56-59) and rock physics experiments (50, 54), give strong 192 support to the type of model discussed here. A heterogeneous sheared boundary layer source model not 193 only explains a variety of geophysical data but has provided evidence that midplate volcanoes are often 194 underlain by higher wavespeeds at shallow depths than occur under ridges and some volcano-free areas 195 (43, 44, 57), suggesting that melt extraction may have created high wavespeed areas. Large offsets

196 between deep low wavespeed mantle features and volcanoes are commonly observed suggesting that 197 they may be unrelated.

\section{Summary}

200 The causes of low velocities, high attenuation and anisotropy in the Earth's upper mantle have 201 recently become controversial. The plate tectonic paradigm for intraplate volcanism, which involves 202 stress release of indigenous melts in the LVZ, has been challenged with arguments that assert that 203 melts do not occur in the LVZ or that if they do they drain out quickly or that even if they don't 204 drain out the effect is too small to explain the seismic observations (15-17). The theory used, 205 however, does not explain the laboratory data on partially molten materials that motivated the idea in 206 the first place $(1,21)$. This apparent paradox is due to the neglect of the pertinent physics. Models 207 that claim to rule out upper mantle melts assume that a melt phase is an unreactive component that 208 can be accounted for by volume averaging and conclude that small amounts of melt do not have a 209 large effect on seismic velocities $(15,16)$. These studies ignore experiments and theory that show the 210 ability of small amounts of melt to dramatically modify physical properties, including permeability, 211 through chemical effects $(7,8)$. The interaction between seismic waves and melt, and of migrating 212 melts with the matrix, are significant. The effects of fluids are also not entirely microscopic; the 213 presence of large lamellae and sills are consistent with observed seismic anisotropy in the LVZ (10, 
214 24).

215 Taken as a whole, the seismic structure of the LVZ, including attenuation, sharp boundaries, and 216 anisotropy are best explained using a dynamic melting model. The implication is that the LVZ

217 contains melt and that it is not only a plausible source, but it is the most likely source for mid-plate

218 and large igneous province volcanism $(4,60,61)$. Sources deeper than $\sim 300 \mathrm{~km}$ may be too cold (24, 219 29, 39), to explain the hottest Hawaiian basalts (46).

220 LVZs that occur sporadically near 400 and $700 \mathrm{~km}$ depth $(63,64)$ may have similar explanations 221 (2, 23) and do not require recycling of water and crustal components to the base of the mantle and 222 back through a water filter [see S12]. Many geochemical and geodynamic models assume whole 223 mantle convection at the outset, and ignore the effects of dynamic melting and $\mathrm{CO}_{2}$ when interpreting 224 LVAs $(62,64)$.

225

\section{Appendix 1 - Dynamic melting}

227 It is now well established that seismic waves can interact with phase changes and that this lowers 228 seismic wavespeeds $(1,7,8)$. Several experimental studies of elastic properties during the melting 229 process $(1,18,22,23)$ were used in earlier conclusions about the role of melts in the LVZ. One 230 investigation (1) used a salt-water mixture that produced a binary melting relation (Fig. 2). Two 231 compositions were studied, $1 \%$ and $2 \% \mathrm{NaCl}$ solutions, that yielded a factor of two difference in the 232 amounts of melt $(F)$ at a given temperature. It was found that at the eutectic temperature of the $1 \%$ [2\%] 233 system, the formation of $3 \%$ [6\%] liquid, was accompanied by a shear modulus drop of about $25 \%$ $234[60 \%]$ and a bulk modulus drop of $8 \%$ [30\%]. Furthermore, for the same melt content, the bulk modulus 235 decrease in the low-salt system, relative to the unmelted solid, was about $1 / 3$ and the shear modulus 236 decrease was $1 / 2$ of that for the high-salt system. In other words, wavespeeds are not simply related to 237 melt content.

238 Laboratory $(1,7,8,18,21-23)$ and seismic results $(10-12,14)$ challenge the standard static two239 phase aggregate models (15) for partial melting in three respects: 1) The shear, longitudinal and bulk 240 moduli all abruptly decrease at the onset of melting and by more than that due to the geometric effects of 241 such small melt volumes, 2) The moduli drops are not determined only by the fraction of melt present 242 and the melt geometry. The dynamic melting model (21) is compatible with these observations since it is 243 the pressure derivative, $d F / d P$, not $F$, that dictates the amount of decrease, and 3) The observed velocity 244 changes for $\mathrm{P}$ waves and $\mathrm{S}$ waves are comparable, both at the top and the base of the LVZ and the 
245 inferred changes in bulk modulus, are significant $(8,21-23)$. The onset of melting of peridotite (21) is 246 associated with a relative drop in $\mathrm{P}$ velocity that is equal to the relative drop in shear velocity. A seismic 247 wave interacting with a part of the mantle at its solidus is slowed more than a wave interacting with an 248 equal amount of melt at higher temperatures (1, 7, 8, 18, 21-23), consistent with dynamic melting, which 249 depends on $d F / d P$. This interaction also explains the large effect on bulk modulus and the anelasticity of 250 the LVZ. Hence, laboratory studies support the dynamic melting model but are incompatible with inert 251 two-phase aggregate models (15).

252 While there are a variety of mechanisms that can explain decreasing seismic wavespeeds with depth $253(9,24,35,36,65)$, the logically dubious argument is sometimes made that since such mechanisms exist, 254 the partial melt explanation can be ruled out (15). Many of these mechanisms, however, are concerned 255 only with relaxation of the shear modulus and do not explain the seismic discontinuities at the 256 boundaries of the LVZ, the strong seismic anisotropy in the LVZ and the laboratory experiments on 257 dynamic melting that led to the suggestion in the first place $(1,4)$. At the other extreme, some studies 258 assume that any LVZ is due to dehydration melting and confirms the presence of large amounts of water 259 at depth in the mantle.

260 Some arguments against partial melting refer to laboratory studies that claim to observe large 261 reductions in wavespeeds at subsolidus conditions. However, these studies actually involved melting at 262 grain boundaries or unacounted for losses to the apparatus $(18,65)$. Minimum LVZ wavespeeds have 263 been overestimated and large subsolidus temperature derivatives for Vs have been used in the arguments 264 against the need for partial melting in the $\operatorname{LVZ}(15,35,36)$; low-resolution tomographic models do not 265 recover the lowest wavespeeds in the boundary layer $(13,56)$. Tomography, by its nature, averages over 266 large volumes. Melting in the LVZ of the upper boundary layer appears to be unavoidable, even for the 267 low ambient temperatures and relatively refractory compositions that have been adopted in laboratory 268 experiments $(16,21,46)$.

Two of the most recent arguments that have been used against the presence of melt in the shallow mantle assume an unsheared homogeneous matrix with no permeability barriers, and extraordinarily efficient melt extraction mechanisms $(15) ; 1)$ melts in the mantle do not wet grain boundaries and hence the ability of partial melt to influence physical properties is limited, and 2) it difficult to retain melt in a

273 gravity field; gravity will effectively drain out all the melt and gravity-driven fluid dynamic instabilities 274 will destroy melt-rich layers. The same arguments, if valid, could be used against the water filter model 275 (62), that assumes that melts accumulate at 410 and $700 \mathrm{~km}$ depths. 
Arguments to the effect that partial melt models for the low velocity zone can be ruled out based on the wettability of grain boundaries, the aspect ratio of thin film melts and dihedral angles are viewing the 278 phenomenon at the wrong scale. In a polyphase mélange the melt pockets are sheared into discontinuous lamellae that have the same effects on long wavelength seismic waves as grain boundary films but which are independent of wetting angles and surface tension $(10,24)$.

\section{Appendix 2 - The Transition Zone water filter model and dehydration melting}

In addition to the low-velocity zone at the top of the mantle, others have been detected at depths of roughly $350-370,400-410$ and $600-700 \mathrm{~km}(46,62-66)$. These have been explained by $\mathrm{CO}_{2}$ and the accumulation of eclogite, or other crustal components. In the water filter model (62) it is assumed that broad upwelling currents dehydrate and melt as they pass through the 410-km discontinuity, leaving water, melt and impuritities behind. Lower mantle LVZs are attributed to diffuse downwellings that dehydrate as they sink below $650 \mathrm{~km}$ (64), whole mantle convection being assumed. Transition zone properties, however, are consistent with cold mantle accumulating above, depressing the $650-\mathrm{km}$ discontinuity, displacing older warmer mantle upwards, elevating the 410; they are not consistent with whole mantle convection with throughgoing slabs and hot plumes (19). Alternative explanations of deep LVAs are $\mathrm{CO}_{2}$, segregated basalt, metastability, underplating and interaction of the seismic waves with

294 phase changes. None of these require whole mantle convection, deep slab penetration or transport of 295 water into the lower mantle and then back again to $410 \mathrm{~km}(9,24)$.

296 Low-velocity anomalies (LVAs) are often simply attributed to excess temperature or water content, small grain size or decompression and dehydration melting, but the actual situation is much more complex and requires mechanisms for causing these phenomena. A horizontal LVZ can be due to the effects of $\mathrm{CO}_{2}$, ponding under a permeability barrier or a negative Clapyron slope boundary, shearing, metastable phases or the dynamic effects discussed in this paper. Deep LVAs can form at solid-solid phase boundaries and do not require the presence of either water or of melt $(7,8)$.

The transition-zone water filter and dehydration melting models $(62,64)$ assume that water is the 303 main 'impurity' that lowers melting points and that the transition zone is the major water reservoir in the 304 mantle. Melts and impurities accumulate above and below the transition zone but not in the shallow LVZ 305 (15). In these models, the global mantle flow pattern is dominated by slab-related localized downwelling 306 currents and diffuse upwelling flow. This is the precise opposite of the mantle plume model, which 
307

308

309

310

311

312

313

314

315

316

317

318

319

320

321

322

323

324

325

326

327

328

329

330

331

332

333

334

335

336

337

338

339

340

341

342

343

344

345

346

347

348

assumes narrow focused upwellings (plumes) and diffuse downflow. Alternatively, ancient ambient depleted mantle at the base of the $\mathrm{TZ}$ is forced up by the downward flux of subducting slabs and becomes the passive depleted upwellings that fuel midocean ridges and near-ridge hotspots. Those that rise midplate interact with the surface boundary layer and pick up the impurities and chemical components that define midplate basalts (24). Volatiles and impurities are sheared into the surface boundary layer and this, not the regions above the TZ or the core, is the source of Hawaii, Samoa, Yellowstone and other intraplate volcanoes.

\section{References}

1. Spetzler HA, Anderson DL (1968) The effect of temperature and partial melting on velocity and attenuation in a simple binary system. J. Geophys. Res. 73: 6051-6060.

2. Birch F (1969) in: The Earth's Crust and Upper Mantle, Geophys. Monograph 13. (Am. Geophys. Union, Washington, DC, pp 18-36.

3. Birch F (1970) Interpretations of the low velocity zone. Phy. Earth Planet Int. 3: 178-181.

4. Anderson DL, Sammis, CG (1970) Partial melting in the upper mantle. Phys. Earth Planet. Inter. 3: 41-50.

5. Anderson DL, Spetzler HA (1970) Partial melting and the low-velocity zone. Phys. Earth Planet. Inter. 4: 62-64.

6. Anderson DL (1970) Petrology of the mantle. Min. Soc. Am. Spec. Pap. 3: 85-93.

7. Vaisnys JR (1968) Propagation of Acoustic Waves through a System Undergoing Phase Transformations. J. Geophys. Res. 73: 7675-7683.

8. Li L, Weidner DJ (2008) Effect of phase transitions on compressional-wave velocities in the Earth's mantle. Nature 454: 984.

9. Anderson DL (2007) New Theory of the Earth (Cambridge Univ. Press, New York).

10. Kawakatsu $\mathrm{H}$ et al. (2009) Seismic evidence for sharp lithosphere-asthenosphere boundaries of oceanic plates. Science 324: 499-502.

11. Collins J, Vernon F, Orcutt J, Stephen R. (2002) Upper mantle structure beneath the Hawaiian swell: constraints from the ocean seismic network pilot experiment. Geophys. Res. Lett. 29: doi:10.1029/2001GL0133022002.

12. Gaherty JB, Jordan TH, Gee LS (1996) Seismic structure of the upper mantle in a central Pacific corridor. J. Geophys. Res. 101: 22291-22309.

13. Tan Y, Helmberger DV (2007) Trans-Pacific upper mantle shear velocity structure. J. Geophys. Res. 112: doi:10.1029/2006JB004853.

14. Regan J, Anderson DL (1984) Anisotropic models of the upper mantle. Phys. Earth and Planet. Int. 35: 227-283.

15. Karato, SI (2013) Does partial melting explain geophysical anomalies? Physics of the Earth and Planetary Interiors: doi:http://dx.doi.org/10.1016/j.pepi.2013.08.006.

16. Hirschmann MH (2010) Partial melt in the oceanic low velocity zone. Phy. Earth Planet Int. 179: 60-71.

17. Gribb TT, Cooper RF (2000) The effect of an equilibrated melt phase on the shear creep and attenuation behavior of polycrystalline olivine. Geophys. Res. Lett. 27: 2173-2352. 
349

18. Berckhemer H (1980) High-temperature anelasticity and elasticity of mantle peridotite - reply. Phys. Earth Planet. Inter. 23: 235.

19. Anderson DL (2013) The persistent mantle plume myth. Austr. J. of Earth Sci. 60: 657-673.

20. Takei Y (2000) Acoustic properties of partially molten media studied on a simple binary system with a controllable dihedral angle. J. Geophys. Res. 105: 16,665-16,682 doi:10.1029/2000JB 900124.

21. Li L, Weidner DJ (2013) Effect of dynamic melting on acoustic velocities in a partially molten peridotite. Phys. Earth Planet. Int. 222: 1-7.

22. Mizutani H, Kanamori H (1964) Variation in elastic wave velocity and attenuative property near the melting temperature. J. Phys. Earth 12: 43-49.

23. Sato H, Sacks IS, Murase T (1989) The use of laboratory velocity data for estimating temperature and partial melt fraction in the low-velocity zone-comparison with heat-flow and electricalconductivity studies, J. Geophys. Res. 94: 5689-5704.

24. Anderson DL (2010) Hawaii, Boundary layers and ambient mantle-geophysical constraints. $J$. Petrology: doi: 10.1093/petrology/egq068.

25. Jackson MG et al. (2010) Evidence for the survival of the oldest terrestrial mantle reservoir. Nature 466: 853-856 doi:10.1038/Nature09287.

26. Meibom A, Sleep NH, Zahnle K, Anderson DL (2005) in Plates, Plumes and Paradigms, eds. Foulger GR, Natland DC, Presnall DC, Anderson DL(Geol. Soc. Amer. Spec. Paper 388), pp. 347-363.

27. Huang S, Lee C-TA, Yin Q-Z (2014) Missing lead and high $3 \mathrm{He} / 4 \mathrm{He}$ in ancient sulfides associated with continent formation. Nature Scientific Reports 4: 5314 doi:10.1038/srep05314.

28. Fitton G (2007) The OIB paradox. GSA Spec. Papers 430: 387-41.

29. Moore WB (2008) Heat transport in a convecting layer heated from within and below. J. Geophys. Res. 113: 2156-2202 doi:10.1029/2006JB004778.

30. Hart SR, Hauri EH, Oschmann LA, Whitehead JA (1992) Mantle plumes and entrainment: isotopic evidence. Science 256: 517-520 doi:10.1126/science.256.5056.517.

31. McKenzie D, Bickle MJ (1988) The volume and composition of melt generated by extension of the lithosphere. J. Petrology 29: 625 - 679.

32. Humphreys ED, Schmandt B (2003) Looking for mantle plumes. Phys. Today 64: 34-39.

33. DePaolo DJ, Manga M (2003) Deep origin of hotspots - the mantle plume model. Science 300: 920921.

34. Hoffman AW, Hart SR (1978) Assessment of local and regional isotopic equilibrium in the mantle. Earth Planet. Sci. Lett. 38: 44-62.

35. Priestley K, McKenzie D (2006) The thermal structure of the lithosphere from shear wave velocities. Earth Planet. Sci. Lett. 244: 285-301.

36. Stixrude L, Lithgow-Bertelloni C (2005) Mineralogy and elasticity of the oceanic upper mantle: Origin of the low velocity zone. J. Geophys. Res. 110: doi:10.1029/2004JB002965.

37. Schmandt B, Humphreys ED (2010) Complex subduction and small-scale convection revealed by body wave tomography of the western U.S. upper mantle. Earth and Planet. Science Letters 297: 435-445, doi:10.1016/j.eps1.2010.06.047.

38. Hillier JK, Watts AB (2005) Relationship between depth and age in the North Pacific Ocean. $J$. Geophys. Res. 110: doi:10.1029/2004JB003406.

39. Jeanloz R, Morris S (1987) Is the mantle geotherm subadiabatic. Geophys. Res. Lett. 14: 335-338. 
394

395

396

397

398

399

400

101

102

103

104

105

106

107

108

109

$+10$

$+11$

112

113

114

$+15$

116

417

118

119

$+20$

$+21$

122

123

$+24$

125

126

127

128

$+29$

130

131

$+32$

$+33$

134

$+35$

136

$+37$

138

439

40. Tackley P, Stevenson D, Glatzmaier G, Schubert G (1993) Effects of an endothermic phase transition at $670 \mathrm{~km}$ depth in a spherical model of convection in the Earth's mantle. Nature 361: 699-704.

41. Schuberth BS et al. (2009) Thermal versus elastic heterogeneity in high-resolution mantle circulation models with pyrolite composition. Geochem. Geophys. Geosyst. 10: doi:10.1029/2008GC002235.

42. Gale A, Langmuir CH, Dalton CA (2014) The global systematics of ocean ridge basalts and their origin. J. Petrology 55: 1051-1082 doi:10.1093/petrology/egu017.

43. M. H. Ritzwoller MH, N. M. Shapiro NM, S.-J. Zhong S-J (2004) Cooling history of the Pacific lithosphere. Earth Planet Sci. Lett. 226: 69-84.

44. Maggi A, Debayle E, Priestley K, Barroul G (2006) Multimode surface waveform tomography of the Pacific Ocean: a closer look at the lithospheric cooling signature. Geophys. J. Int. 166: 13841397.

45. Haase KM (1996) The relationship between the age of the lithosphere and the composition of oceanic magmas. Earth Planet Sci. Lett. 144: 75-92.

46. Presnall DC, Gudfinnsson GH (2011) Oceanic volcanism from the low-velocity zone-geodynamic implications. J. Petrology 52: 1533-1546.

47. Wilson JT (1963) A possible origin of the Hawaiian Islands. Canadian J. Phys. 41: 863-870.

48. Van Ark E, Lin J (2004) Time variation in igneous volume flux of the Hawaii-Emperor hot spot seamount chain. J. Geophys. Res. 109: doi:10.1029/2003JB002949.

49. Hart SR et al. (2000) Vailulu'u undersea volcano: The New Samoa. Geochem. Geophys. Geosyst. 1: Paper number 2000GC00010.

50. Holtzman BK, Kendall J-M (2010) Organized melt, seismic anisotropy, and plate boundary lubrication. Geochem. Geophys. Geosyst. 11: doi:10.1029/2010GC003296.

51. Deuss A, Woodhouse JH (2002) A systematic search for mantle discontinuities using SS-precursors. Geophys. Res. Lett. 29: 90-1 - 90-4 doi: 10.1029/2002GL014768.

52. Hirth G, Kohlstedt DL (1996) Water in the oceanic upper mantle: implications for rheology, melt extraction and the evolution of the lithosphere. Earth Planet. Sci. Lett. 144: 93-108.

53. Karato S (2012) On the origin of the asthenosphere. Earth Planet. Sci. Lett. 321/322: 95-103.

54. Holtzman BK et al. (2003) Stress-driven melt segregation in partially molten rocks. Geochem. Geophys.Geosyst. 4: doi:10.1029/2001GC000258.

55. Ricard Y, Matas J, Chambat F (2009) Seismic attenuation in a phase change coexistence loop. Phys. Earth Planet. Inter. 176: 124-131.

56. Styles E et al. (2011) Synthetic images of dynamically predicted plumes and comparison with a global tomographic model. Earth Planet. Sci. Lett. 311: 351-363.

57. Katzman R, Zhao L, Jordan TH (1998) High-resolution, two-dimensional vertical tomography of the central Pacific mantle using $\mathrm{ScS}$ reverberations and frequency-dependent travel times. $J$. Geophys. Res. 103: 17933-17971.

58. Goes S, Eakin CM, Ritsema J (2013) Lithospheric cooling trends and deviations in oceanic PP-P and SS-S differential traveltimes. J. Geophys. Res. 118: 996-1007 doi:10.1002/jgrb.50092.

59. Leahy GM et al. (2010) Underplating of the Hawaiian Swell: Evidence from teleseismic receiver functions. Geophys. J. Int. 183: 313-329.

60. Cañón-Tapia E (2010) Origin of Large Igneous Provinces: The importance of a definition. in Geological Society of America Special Paper 470, eds Cañón-Tapia E, Szakács A, pp. 77101.

61. Silver PG et al. (2006) Understanding cratonic flood basalts. Earth Planet. Sci. Lett. 245: 190- 
140

174 calculations (16). 425: 39-44. 1268.

\section{Figure Captions} (panel B).

201 doi: 10.1016/j.epsl.2006.01.050.

62. Bercovici D, Karato S (2003), Whole mantle convection and transition-zone water filter. Nature

63. Blum J, Shen Y (2004) Thermal, hydrous, and mechanical states of the mantle transition zone beneath southern Africa. Earth Planet. Sci. Lett. 217: 367-378.

64. Schmandt B et al. (2014) Dehydration melting at the top of the lower mantle. Science 344: 1265-

65. McCarthy C, Takei Y, Hiraga T (2011) Experimental study of attenuation and dispersion over a broad frequency range: 2 . The universal scaling of polycrystalline materials. J. Geophys. Res. 116: doi:10.1029/2011JB008384.

66. Keshav S, Gudfinnsson GH, Presnall D (2011) Melting Phase Relations of Simplified Carbonated Peridotite at 12-26 GPa in the Systems CaO-MgO- $\mathrm{SiO}_{2}-\mathrm{CO}_{2}$ and $\mathrm{CaO}-\mathrm{MgO}-\mathrm{Al}_{2} \mathrm{O}_{3}-\mathrm{SiO}_{2}-\mathrm{CO}_{2}$ : Highly Calcic Magmas in the Transition Zone of the Earth. J. Petrology 52: 2265-2291.

Figure 1. Seismic velocities in the LVZ (panel A; modified from refs. 14 and 43) are a function of T and the number-density of melt-rich lamellae. The velocities $\mathrm{V}_{\mathrm{SV}}$ of SV waves are mainly controlled by the low-velocity melt-rich or low-rigidity lamellae illustrated schematically in panel B. Decreases in velocities are caused by large positive temperature gradients and partial melting. The SV-SH splitting is caused by melt-rich lamellae shown schematically in panel $\mathrm{C}$, which are sheared by plate motion as indicated by the arrow. The strong increase in velocities below about $150 \mathrm{~km}$, which has been considered enigmatic (36), is due to subadiabatic or negative temperature gradients (39-41)

Figure 2. Decreases in longitudinal and shear velocities across the solidus in dilute (1\% and $2 \%)$ $\mathrm{NaCl}-\mathrm{H}_{2} \mathrm{O}$ solutions $(1)$. The temperatures are scaled to the eutectic temperature $\left(\mathrm{T}^{*}=-21.1 \mathrm{C}\right)$ as (T$\left.\mathrm{T}^{*}\right) / \mathrm{T}^{*} \mid$. The velocities VL and VS are scaled to $\mathrm{V}_{0}$, the corresponding values in pure ice at the lowest measured temperature $\left(\mathrm{T}-\mathrm{T}^{*}\right) /\left|\mathrm{T}^{*}\right|=-0.6$. The percent of liquid melt relative to solid ice is also indicated. This provides an analog to the $\mathrm{G}$ discontinuity that separates the high wavespeed seismic lid from the low velocity zone (LVZ). The theory that explains these laboratory results has been confirmed at seismic frequencies (21). The effects of aligned melt-rich lamellae and dynamic melting accentuate the effects of small degrees of melt, particularly on the longitudinal and bulk moduli. In 
176

177
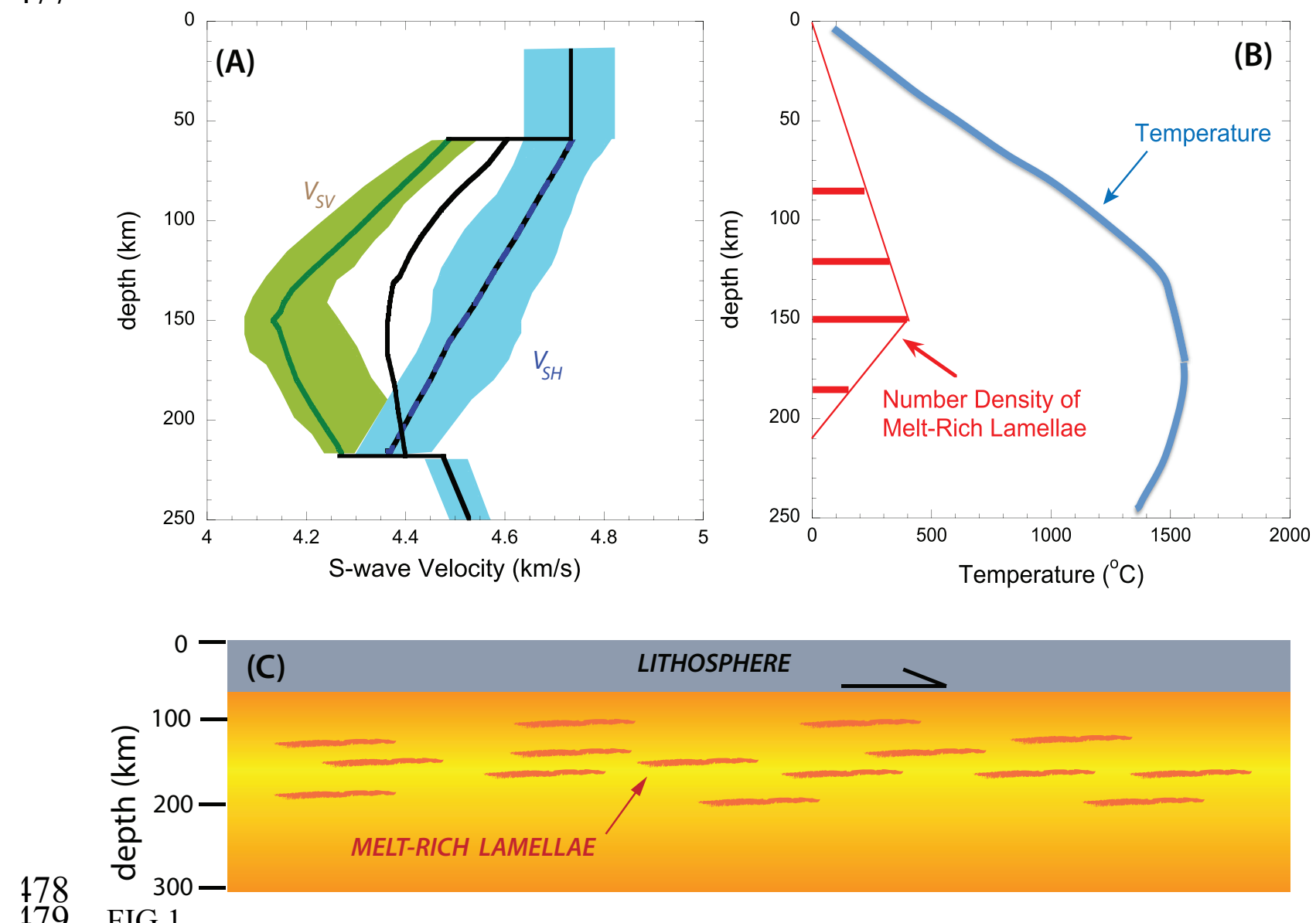

179 FIG 1

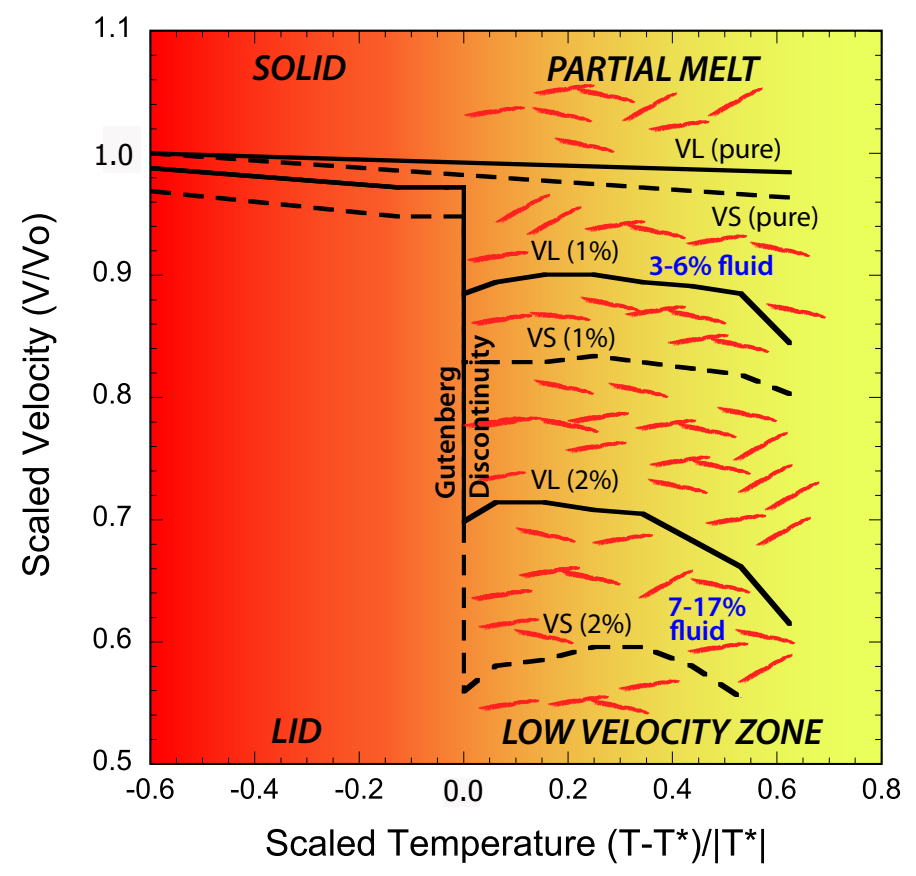

181 FIG 2 